\title{
OSTEOPROTEGERIN AND BONE DENSITY
}

\author{
David Stejskala, Martin Zurek $^{\mathrm{b}}$, Josef Bartek ${ }^{\mathrm{c}}$, Libor Jedelskýa ${ }^{\mathrm{a}}$, Viktor Růžička ${ }^{\mathrm{a}}$
}

\author{
${ }^{a}$ Department of Laboratory Medicine, Hospital Šternberk, Czech Republic, Jivavská 20, 78516 \\ ${ }^{b}$ Department of Internal Medicine, Hospital Šternberk, Czech Republic, Jivavská 20, 78516 \\ ${ }^{c}$ Institute of Medical Chemistry and Biochemistry, Faculty of Medicine, Palacky University, Olomouc
}

Received: January 10, 2002

Key words: Osteoprotegerin / Bone density / Osteoporosis

Aim of study was determine if a correlation exists between bone mass density and concentration of osteoprotegerin.

We examined the group of 199 patients of mean age of 63 years. Of the group under study, 31 patients had normal bone density ( $\mathrm{T}$ score $>-1$ and $<1$ ) and 168 probands had osteopenia or osteoporosis $(\mathrm{T}<-1)$.

Persons with normal BMD values had median values of OPG $60.8 \mathrm{ng} / \mathrm{l}$, while patients with reduced bone density had median values of $73 \mathrm{ng} / \mathrm{l}$ OPG. Cut-off for reduction of bone density was $128 \mathrm{ng} / \mathrm{l} \mathrm{OPG}$.

We demonstrated that OPG concentrations vary inversely with bone density values (correlation coefficient -0.31 ).

These results suggest that determination of OPG could allow discrimination of individuals with normal bone density and those with reduced bone density.

\section{INTRODUCTION}

Osteoprotegerin (OPG) and its ligand (OPGL) are cytokines regulating osteoclastogenesis. OPGL binds to receptors on the surface of preosteoclasts and stimulates their differentiation into active osteoclasts. This leads to osteoresorption. OPG inhibits this osteoclastogenesis (OPG is secreted by osteoblasts, and binds to OPGL, thus inhibiting maturation of osteoclasts and osteoresorption) $)^{1}$.

The degree and activity of osteoresorption depend mainly on the balance between OPG and its ligand (OPGL); factors increasing OPGL expression mostly reduce OPG expression and vice versa.

Previous experiments have shown that OPG-deficient mice have osteoporosis (OPGL was not regulated, advanced osteoresorption was observed $)^{1}$. Previous clinical studies have demonstrated that OPG values correlate with $\mathrm{BMD}$, although no correlation has been established between OPG concentrations and bone fractures $^{2,3}$.

\section{AIM OF THE STUDY}

To determine if a correlation exists between BMD and OPG in patients with varying degrees of reduced bone density.

\section{METHODS}

We examined patients at the Metabolic Outpatients' Center, Hospital Sternberk, who were under follow up treatment for osteopathy or recurrent urolithiasis $(\mathrm{n}=199)$. All conditions for this study met the Human Subjects criteria recognized as valid in the Czech Republic.

All individuals were examined for OPG concentration (ELISA, BioVendor). The method yielded satisfactory analytical performance (sensitivity $2 \mathrm{ng} / \mathrm{l}$, CV intraassay $<5.6 \%$ with 10 repetitions at concentration of 50 and $300 \mathrm{ng} / \mathrm{l}, \mathrm{CV}$ interassay $<8.9 \%$ over 5 days at concentrations of 50 and $300 \mathrm{ng} / \mathrm{l}$, linearity within $1000 \mathrm{ng} / \mathrm{l})$.

We also determined the Bone isoform of alkaline phosphatase (ELISA, METRA), Osteocalcin (ELISA, METRA), DPD/creatinine index (ELISA, METRA), Calcium concentration in the serum and urine (FAES), Phosphor of the serum and urine (colorimetry, BioVendor), Magnesium in the serum and urine (colorimetry, BioVendor) and Creatinine in the serum and urine (Jaffe, BioVendor). BMD was determined by densitometric examination of the skeleton (DeXA Hologic, 2000).

The probands were divided into groups of individuals with normal bone density BMD individuals with reduced bone density having the character of osteopenia or osteoporosis (T score $<-1$ ). Prerequisite for the study was the fact that values of $\mathrm{T}$ score on $\mathrm{L}$ spine and femur should discriminate all probands always in the same group (normal BMD, decreased BMD).

All proband values were subjected to statistical analysis (Kruskal-Wallis tests, ANOVA and discrimination analysis - software SPSS). 


\section{RESULTS}

We examined a group of 199 patients of mean age of 63 years (28-79 years). Of the group under study, 31 patients had normal bone density ( $\mathrm{T}$ score $>-1$ and $<1$ ) and 168 probands had osteopenia or osteoporosis $(\mathrm{T}<-1)$. Ninety percent of probands in the group with pathological BMD were treated by antiresorption preparations combined with preparations of calcium or vitamin D.

Persons with normal BMD values had median values of OPG $60.8 \mathrm{ng} / \mathrm{l}(19-128 \mathrm{ng} / \mathrm{l})$, while patients with reduced bone density had median values of $73 \mathrm{ng} / \mathrm{l} \mathrm{OPG}$ (9-1000 ng/l). Cut-off for reduction of bone density was 128 ng/l OPG. All individuals with higher OPG values had a reduced bone density. The data demonstrated a negative linear correlation between bone density and OPG concentration (correlation coefficient -0.31).

Discrimination analysis revealed that OPG could be used to correctly assign $79 \%$ of cases to the correct determined group; $100 \%$ of probands with reduced DMB were rejected by analysis of OPG values as normal (graph 1, Figure 1).

Despite the correlation of OPB with reduced bone density, the role of OPG in osteoporosis remains unclear. For example, an increase of OPG above a certain value may be a secondary factor associated with a reaction of the individual to the loss of bone mass (e. g. induced by therapy -61 probands with pathological BMD were treated by antiresorption preparations - HRT, calcitonine or alendronate $)^{2}$.

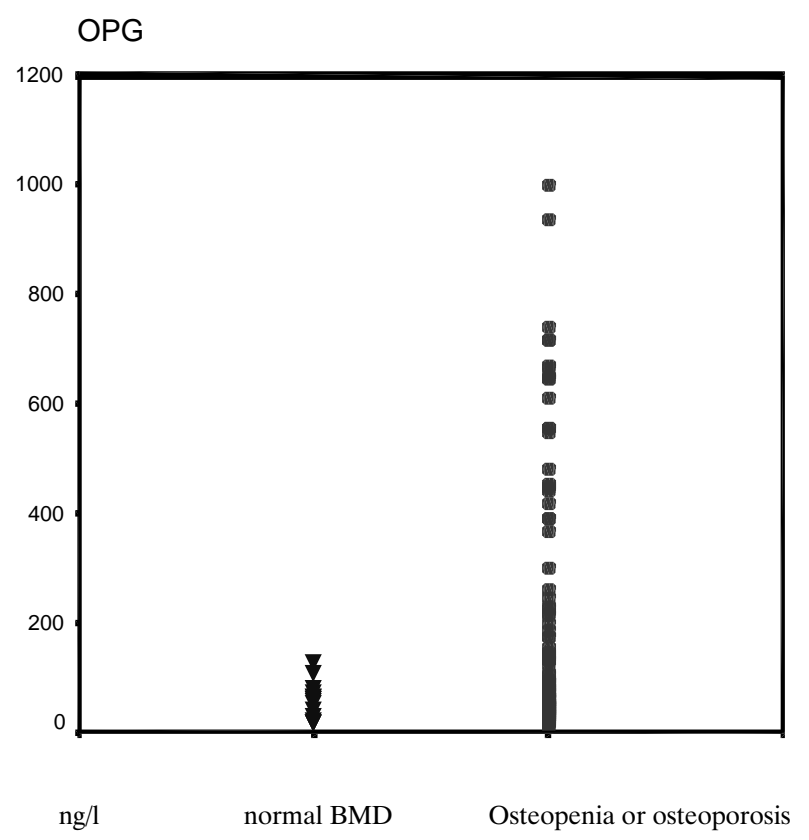

Table 1. Classification into stratification groups according to all parameters measured Discrimination analysis

\begin{tabular}{lcc}
\hline & $\begin{array}{l}\text { Prediction } \\
\text { of normal BMD }\end{array}$ & $\begin{array}{l}\text { Prediction } \\
\text { of pathological BMD }\end{array}$ \\
\hline Really normal BMD & 79 & 21 \\
Really pathological BMD & 18 & 82 \\
\hline Correct classification in 79\% of cases &
\end{tabular}

\section{CONCLUSION}

We demonstrated that OPG concentrations in our study groups vary inversely with bone density values. These results suggest that determination of OPG could allow discrimination of individuals with normal bone density and those with reduced bone density.

\section{REFERENCES}

1. Shalhoub, V., Faust, J., Boyle, W. J. et al. (1999) Osteoprotegerin and osteoprotegerin ligand effects on osteoclasts formation from human peripheral blood mononuclear cell precursors. J. Cell. Biochem. 72, 251-261.

2. Browner, W. B., Li-Yang, L., Cummingsa, S. R. (2001) Associations of Serum Osteoprotegerin Levels With Diabetes, Stroke, Bone density, fractures and mortality in Elderly Women. The J of Clin. Endocrinology and Metabolism 86, 631-637.

3. Yano, K., Shibata, O., Mizuno, A., Kobayashi, F., Higashio, K., Morinaga, T., Tsuda, E. et al. (2001) Immunological study on circulating murine osteoprotegerin/osteoclastogenesis inhibitory factor (opg/ocif): possible role of opg/ocif in the prevention of osteoporosis in pregnancy. Biochem. Biophys. Res. Commun. 288, 217-224. 